\title{
Levofloxacin-Associated Neurotoxicity in a Patient with a High Concentration of Levofloxacin in the Blood and Cerebrospinal Fluid
}

\author{
Masashi Nishikubo (D), Maki Kanamori and Hiroaki Nishioka * \\ Department of General Internal Medicine, Kobe City Medical Center General Hospital, Kobe, \\ Hyogo 6500047, Japan; mnishi90@yahoo.co.jp (M.N.); maki1152@kcho.jp (M.K.) \\ * Correspondence: nishiokahiroaki@hotmail.com; Tel.: +81-78-302-4321
}

Received: 28 May 2019; Accepted: 10 June 2019; Published: 12 June 2019

\begin{abstract}
Neurotoxicity is a rare and intolerable adverse effect associated with levofloxacin therapy, whose diagnosis has mostly been reported based on medical history rather than quantitative measures in the blood. We report a 68-year-old man with levofloxacin-associated encephalopathy and myoclonus with high levels of levofloxacin in the blood and cerebrospinal fluid. After hemodialysis, these decreased, and his symptoms rapidly improved. An electroencephalogram was also normal. This case showed the concentration of levofloxacin to be clearly related to levofloxacin-associated neurotoxicity. Therefore, an estimation of its concentration may contribute to accurate diagnosis.
\end{abstract}

Keywords: Levofloxacin; concentration; encephalopathy; myoclonus; hemodialysis

\section{Introduction}

Levofloxacin is a third-generation fluoroquinolone antibiotic used for treatment of a wide range of bacterial infections [1]. Neurotoxicity caused by levofloxacin is a known but rare adverse effect, with symptoms including headache, dizziness, sleep disturbance, psychosis, delirium, seizures, myoclonus, and others [2]. These symptoms are often intolerable and compel the discontinuation or change of treatment with levofloxacin. A high concentration of levofloxacin in the blood is believed to cause neurotoxicity, but few studies have specifically examined this in affected patients. Instead, nearly all cases have been diagnosed based on a history of prior exposure to levofloxacin, improvement after its cessation, and exclusion of other causes of neurotoxicity [3-8]. We report a case of levofloxacin-associated encephalopathy and myoclonus clearly related to high concentrations of levofloxacin in the blood and cerebrospinal fluid (CSF).

\section{Case Presentation}

A 68-year-old Japanese man was admitted to our hospital in winter due to disturbed consciousness and difficulty with body movements. Approximately two weeks prior, he had experienced fever and generalized edema. Thirteen days before admission, his family physician prescribed levofloxacin at $500 \mathrm{mg} /$ day, furosemide at $20 \mathrm{mg} /$ day, and spironolactone at $25 \mathrm{mg} /$ day for seven days. The patient complied with this and became afebrile, and his edema disappeared. Two days before admission, his wife noticed that his speech was slurred, and he was only able to understand short and simple sentences. On the day of admission, he could not communicate and was unable to speak comprehensibly. He could not move by himself. His past medical history included cerebral palsy with lower limb atrophy, but he could walk using a frame. He had normal mental and intellectual development. He also had chronic kidney disease (CKD) at the stage of G4A3 due to nephrosclerosis and a horseshoe kidney, with a 
creatinine level of around $2.5 \mathrm{mg} / \mathrm{dL}$. He had been treated with nifedipine, doxazosin, and febuxostat and did not use any over-the-counter supplements or illegal drugs.

Upon physical examination, his blood pressure was $65 / 40 \mathrm{~mm} \mathrm{Hg}$, his heart rate was $40 \mathrm{bpm}$, his respiratory rate was 20 breaths/min, and his body temperature was $27.9^{\circ} \mathrm{C}$. His consciousness was registered as E4V1M4 (E: Eye opening, V: Best verbal response, M: Best motor response) on the Glasgow Coma Scale. Accidental hypothermia was suspected, because his room had been cold and he had stayed there throughout the night. He was rewarmed immediately, and his body temperature increased to $35.7^{\circ} \mathrm{C}$, after which his vital signs became stable. However, his consciousness level remained abnormal, and he also showed myoclonus in both upper limbs. The deep tendon reflex of the biceps was normal. Laboratory findings showed a white cell count of $2700 / \mu \mathrm{L}$, a hemoglobin level of $5.9 \mathrm{~g} / \mathrm{dL}$, a platelet count of $16.5 \times 10^{4} / \mu \mathrm{L}$, albumin at $2.0 \mathrm{~g} / \mathrm{dL}$, aspartate aminotransferase at $137 \mathrm{U} / \mathrm{L}$, alanine aminotransferase at $50 \mathrm{U} / \mathrm{L}$, alkaline phosphatase at $288 \mathrm{U} / \mathrm{L}, \gamma$-glutamyl transpeptidase at $13 \mathrm{U} / \mathrm{L}$, blood urea nitrogen at $82.3 \mathrm{mg} / \mathrm{dL}$, creatinine at $3.84 \mathrm{mg} / \mathrm{dL}$, sodium at $142 \mathrm{mEq} / \mathrm{L}$, calcium at $8.0 \mathrm{mg} / \mathrm{dL}$, glucose at $101 \mathrm{mg} / \mathrm{dL}$, thyroid-stimulating hormone at $9.29 \mu \mathrm{U} / \mathrm{mL}$, free $\mathrm{T} 4$ at $1.03 \mathrm{ng} / \mathrm{mL}$, and vitamin B1 at $3.9 \mathrm{~g} / \mathrm{dL}$. Antithyroid peroxidase antibody and antithyroglobulin antibody were undetectable. An arterial blood gas analysis did not show $\mathrm{CO}_{2}$ elevation and indicated mild metabolic acidosis. An electrocardiogram initially showed first-degree atrioventricular block, which became normal sinus rhythm after rewarming. Head-computed tomography and magnetic resonance imaging examinations showed no abnormalities, and an electroencephalogram showed generalized slowing waves. CSF was shown to have a cell count of $0 / \mu \mathrm{L}$, a protein concentration of $68 \mathrm{mg} / \mathrm{dL}$, and a glucose level of $65 \mathrm{mg} / \mathrm{dL}$. Levofloxacin-associated encephalopathy and myoclonus were suspected based on the patient's history of high levofloxacin dosages and present renal function.

The patient was treated through the administration of fluids and furosemide with the aim of levofloxacin being excreted in his urine. Although the patient produced more urine, his creatinine did not return to basal level, and his consciousness level did not improve. Hemodialysis was carried out on days 3 and 5 after admission, and his consciousness level improved and completely recovered by day 7 (Figure 1). The myoclonus disappeared four days after admission. An electroencephalogram on day 15 showed no slowing waves. His Naranjo adverse drug reaction probability scale registered at 7 points, which indicated a probable relationship between his symptoms and adverse drug reactions to levofloxacin [9]. Sixteen days after admission, the patient was transferred to another hospital for rehabilitation. Later, we measured the concentration of levofloxacin in the reserved samples of plasma or CSF, obtained during hospitalization. The plasma concentrations of levofloxacin were 16.9, 16.2, $2.44,0.61$, and $0.71 \mu \mathrm{g} / \mathrm{mL}$ on days $1,2,4,6$, and 7 after admission, respectively (Figure 1). The initial CSF concentration of levofloxacin was $6.81 \mu \mathrm{g} / \mathrm{mL}$.

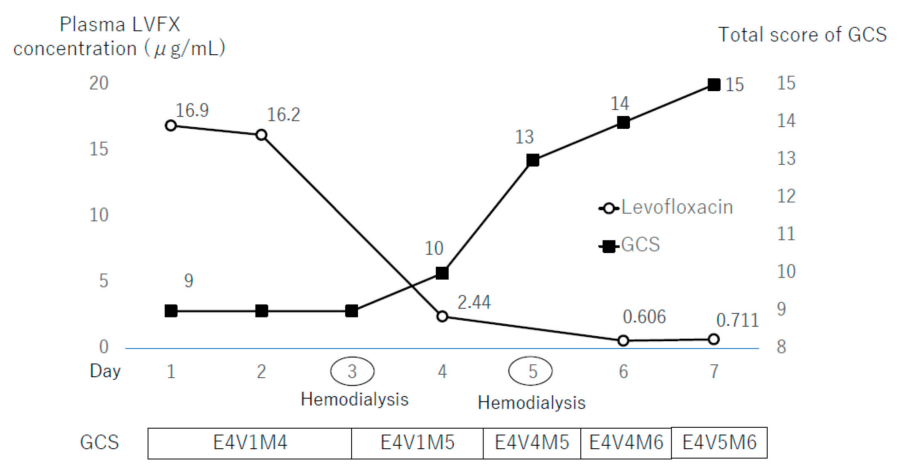

Figure 1. The patient's clinical course. Hemodialysis was conducted three and five days after hospital admission. LVFX: Levofloxacin; GCS: Glasgow Coma Scale; E: Eye opening; V: Best verbal response; $\mathrm{M}$ : Best motor response. 


\section{Discussion}

The clinical course of this patient yielded two important observations. First, a high concentration of levofloxacin in the blood and CSF was observed in conjunction with levofloxacin-associated encephalopathy and myoclonus. Second, hemodialysis was useful in the rapid resolution of levofloxacin-associated neurotoxicity.

Currently, a daily dose of $500 \mathrm{mg}$ or $750 \mathrm{mg}$ of levofloxacin is approved in many countries and is widely used in patients with normal renal function. In healthy volunteers receiving levofloxacin at single doses of $500 \mathrm{mg}, 1000 \mathrm{mg}$, or $1500 \mathrm{mg}$, the mean maximum drug concentration (Cmax) values in plasma were $5.43 \pm 1.76,10.2 \pm 2.92$, and $14.6 \pm 3.49 \mu \mathrm{g} / \mathrm{mL} \pm \mathrm{SD}$, respectively [10]. In the same subjects, the mean time of Cmax (Tmax) values in plasma were $1.7 \pm 0.5,2.0 \pm 0.9$, and $2.2 \pm 1.0$ hours \pm SD [10]. Another study in individuals with normal renal function reported that after daily oral administration of $500 \mathrm{mg}$ of levofloxacin for seven days, the Cmax value was almost the same as that of the first day [11]. Scotton et al. examined the CSF concentration of levofloxacin in five patients with acute bacterial meningitis who were treated with $\beta$-lactam plus levofloxacin (500 mg twice a day. or once a day.) and found a concentration of $1.99 \pm 0.67 \mu \mathrm{g} / \mathrm{mL}$ two hours after dosing without complications [12]. Levofloxacin is excreted from the kidneys via urine [13]. If patients have renal impairment, a dose reduction is urgently necessary in order to avoid the accumulation of levofloxacin and related adverse effects [13]. In fact, impaired renal function has been reported to be a predisposing factor for levofloxacin-associated neurotoxicity [4-8]. However, reports on the concentration of levofloxacin in blood or CSF in patients with levofloxacin-associated neurotoxicity are rare. Our patient had impaired renal function and higher levofloxacin concentrations in both his blood and CSF, even six days after cessation of levofloxacin treatment. This clearly indicated its association with his development of neurotoxicity. Although the safe-limit concentration of levofloxacin in blood has not been established, based on previous reports as well as our current case, we hypothesized that over $15 \mu \mathrm{g} / \mathrm{mL}$ of levofloxacin for some days in the blood might be related to the development of levofloxacin-associated neurotoxicity. The neurotoxic potential of levofloxacin is closely related to its activity on gamma-aminobutyric acid (GABA) receptors and N-Methyl-D-aspartate (NMDA) receptors. Levofloxacin inhibits GABA-A receptors and activates NMDA receptors [14]. A high level of levofloxacin may cause excessive neuronal excitatory signaling, leading to neurotoxic side effects such as encephalopathy and myoclonus. [15]

Normally, treatment for drug-associated neurotoxicity involves the cessation of the causative agents. In previous reports on quinolone-associated encephalopathy, including levofloxacin, rapid improvement was achieved by discontinuation of quinolones only [3-8], and hemodialysis is not routinely recommended [15]. However, this was not the case for the patient in this study, for whom dramatic improvement in his consciousness level and myoclonus was achieved only after hemodialysis. The fact that discontinuation alone did not yield improvement may have been due to delayed renal clearance as a result of acute kidney injury and CKD. After hemodialysis, the plasma concentration of levofloxacin decreased, the patient's consciousness level quickly improved, and myoclonus disappeared. This approach is supported by two additional reported cases of levofloxacin-associated neurotoxicity that showed rapid resolution after hemodialysis in patients with impaired renal function [16].

\section{Conclusions}

A high concentration of levofloxacin in the blood and CSF may be related to levofloxacin-associated encephalopathy and myoclonus and should be included in an examination for accurate diagnosis. Hemodialysis may be a useful treatment for levofloxacin-associated encephalopathy in patients with impaired renal function. 
Author Contributions: M.N. wrote the first draft of the case report; M.N., M.K., and H.N. reviewed the literature; H.N. supervised the manuscript writing, editing, and review.

Funding: This research received no external funding.

Conflicts of Interest: The authors declare no conflicts of interest.

\section{References}

1. Croom, K.F.; Goa, K.L. Levofloxacin: A review of its use in the treatment of bacterial infections in the United States. Drugs 2003, 63, 2769-2802. [CrossRef] [PubMed]

2. Grill, M.F.; Maganti, R.K. Neurotoxic effects associated with antibiotic use: Management considerations. Br. J. Clin. Pharmacol. 2011, 72, 381-393. [CrossRef] [PubMed]

3. Kiangkitiwan, B.; Doppalapudi, A.; Fonder, M.L.; Solberg, K.; Bohner, B. Levofloxacin-induced delirium with psychotic features. Gen. Hosp. Psychiatry 2008, 30, 381-383. [CrossRef] [PubMed]

4. Kocyigit, I.; Dortdudak, S.; Sipahioglu, M.; Unal, A.; Yucel, H.E.; Tokgoz, B.; Eroglu, E.; Oymak, O.; Utas, C. Levofloxacin-induced delirium: is it a dangerous drug in patients with renal dysfunction? Ren. Fail. 2012, 34, 634-636. [CrossRef] [PubMed]

5. Raj, V.; Murthy, T.V. Levofloxacin induced delirium with psychotic features in a young patient. Med. J. Armed Forces India 2013, 69, 404-405. [CrossRef] [PubMed]

6. Host, B.D.; Sloan, W. Orofacial dyskinesia associated with the use of levofloxacin. Ann. Pharmacother. 2014, 48, 142-144. [CrossRef] [PubMed]

7. Lizarraga, K.J.; Lopez, M.R.; Singer, C. Reversible craniocervical dystonia associated with levofloxacin. J. Clin. Mov. Disord. 2015, 2, 10. [CrossRef] [PubMed]

8. Kunder, S.K.; Avinash, A.; Nayak, V.; Tilak, A. A rare instance of levofloxacin induced myoclonus. J. Clin. Diagn. Res. 2017, 11, FD01-FD02. [CrossRef] [PubMed]

9. Naranjo, C.A.; Busto, U.; Sellers, E.M.; Sandor, P.; Ruiz, I.; Roberts, E.A.; Janecek, E.; Domecq, C.; Greenblatt, D.J. A method for estimating the probability of adverse drug reactions. Clin. Pharmacol. Ther. 1981, 30, 239-245. [CrossRef] [PubMed]

10. Noel, G.J.; Goodman, D.B.; Chien, S.; Solanki, B.; Padmanabhan, M.; Natarajan, J. Measuring the effects of supratherapeutic doses of levofloxacin on healthy volunteers using four methods of QT correction and periodic and continuous ECG recordings. J. Clin. Pharmacol. 2004, 44, 464-473. [CrossRef] [PubMed]

11. Shiba, K.; Fukase, H.; Sugiyama, A. Phase I study of levofloxacin healthy and elderly volunteers. Jpn. J. Chemother. 2009, 57, 1-11. (in Japanese).

12. Scotton, P.G.; Pea, F.; Giobbia, M.; Baraldo, M.; Vaglia, A.; Furlanut, M. Cerebrospinal fluid penetration of levofloxacin in patients with spontaneous acute bacterial meningitis. Clin. Infect. Dis. 2001, 33, e109-e111. [CrossRef] [PubMed]

13. Fish, D.N.; Chow, A.T. The clinical pharmacokinetics of levofloxacin. Clin. Pharmacokinet. 1997, 3, 101-119. [CrossRef] [PubMed]

14. Akahane, K.; Tsutomi, Y.; Kimura, Y.; Kitano, Y. Levofloxacin, an optical isomer of ofloxacin, has attenuated epileptogenic activity in mice and inhibitory potency in GABA receptor binding. Chemotherapy 1994, 40, 412-417. [CrossRef] [PubMed]

15. Bhattacharyya, S.; Darby, R.R.; Raibagkar, P.; Gonzalez Castro, L.N.; Berkowitz, A.L. Antibiotic-associated encephalopathy. Neurology 2016, 86, 963-971. [CrossRef] [PubMed]

16. Idrees, N.; Almeqdadi, M.; Balakrishnan, V.S.; Jaber, B.L. Hemodialysis for treatment of levofloxacin-induced neurotoxicity. Hemodial. Int. 2019, 23, E40-E45. [CrossRef] [PubMed] 